\title{
ДО ВИЗНАЧЕННЯ СТРУКТУРИ РОЗВ'ЯЗАННЯ СИСТЕМИ РІВНЯНЬ ГІДРОДИНАМІКИ
}

Анотація: Розглядається задача еквівалентного спрощення виразів, що отримуються при розв'язанні системи квазілійних рівнянь Нав'є-Стокса. Запропоновано алгоритм спрощення, що ґрунтується на використанні теорії ланцюгових дробів.

Ключові слова: інтегральні перетворення, ітераційна схема, конвективнодифузійний перенос, ланцюгові дроби, рівняння Нав'є-Стокса.

У результаті застосування числово-аналітичного методу розв'язання нелінійних рівнянь із частинними похідними [1] до розв'язання системи рівнянь гідродинаміки (рівнянь Нав'є-Стокса) [2] отримують розв'язання для компонент швидкості руху субстанції $u=\left[u_{x}, u_{y}, u_{z}\right]$ (рідинне або газове середовище) у такому вигляді (на першій ітерації):

$$
\begin{aligned}
& u_{x}^{(1)}(x, y, z, t)=u_{x}^{(0)}(x, y, z, t)+ \\
& +\sum_{i=1}^{N_{x}} \sum_{j=1}^{N_{y}} \sum_{k=1}^{N_{z}} X_{i}\left(\alpha_{i}, x\right) Y_{j}\left(\beta_{i, j}, y\right) Z_{k}\left(\gamma_{i, j, k}, z\right)\left[U 1_{i, j, k}^{(1)}+U 2_{i, j, k}^{(1)}\right] e^{-\delta_{i, j, k} t} .
\end{aligned}
$$

Згідно загальної схеми ітераційного процесу лінійна частина розв'язання системи нестаціонарних рівнянь гідродинаміки, яка містить і рівняння Нав'є-Стокса, може бути подана у вигляді ряду:

$$
\begin{aligned}
u_{x}^{(0)}(x, y, z, t)= & \sum_{i=1}^{N_{x}} \sum_{j=1}^{N_{y}} \sum_{k=1}^{N_{z}} X_{u_{x}}\left(\alpha_{i}, x\right) Y_{u_{x}}\left(\beta_{i, j}, y\right) Z_{u_{x}}\left(\gamma_{i, j, k}, z\right) \\
& {\left[U 1_{i, j, k}^{(0)}+U 2_{i, j, k}^{(0)}\right] e^{-\delta x_{i, j, k} t} . }
\end{aligned}
$$

Тут $X_{u_{x}}\left(\alpha_{i}, x\right), Y_{u_{x}}\left(\beta_{i, j} y\right), Z_{u_{x}}\left(\gamma_{i, j, k} z\right)$ - власні функції лінійної частини крайової задачі на власні значення і функції стосовно компоненти швидкості $u_{x}$ [3]. Числа $N_{x}, N_{y}, N_{z}$ визначають кількість членів ряду, що враховуються у розв'язанні з погляду на потрібну точність розв'язання. Величини $U 1_{i, j, k}^{(0)}, U 2_{i, j, k}^{(0)}$ визначаються початковими і межовими умовами відповідної крайової задачі, що підпорядковуються відповідним інтегральним перетворенням.

Аналогічно можна записати розв'язання лінійної частини відносно компонент швидкості $u_{y}, u_{z}$ :

(c) К.С. Бовсуновська, Л.М. Семанишин, 2015 


$$
\begin{aligned}
u_{y}^{(0)}(x, y, z, t)= & \sum_{i=1}^{N_{x}} \sum_{j=1}^{N_{y}} \sum_{k=1}^{N_{z}} X_{u_{y}}\left(\alpha_{i}, x\right) Y_{u_{y}}\left(\beta_{i, j}, y\right) Z_{u_{y}}\left(\gamma_{i, j, k}, z\right) \\
& {\left[V 1_{i, j, k}^{(0)}+V 2_{i, j, k}^{(0)}\right] e^{-\delta_{i, j, k} t} . } \\
u_{z}^{(0)}(x, y, z, t)= & \sum_{i=1}^{N_{x}} \sum_{j=1}^{N_{y}} \sum_{k=1}^{N_{z}} X_{u_{z}}\left(\alpha_{i}, x\right) Y_{u_{z}}\left(\beta_{i, j}, y\right) Z_{u_{z}}\left(\gamma_{i, j, k}, z\right) \\
& {\left[W 1_{i, j, k}^{(0)}+W 2_{i, j, k}^{(0)}\right] e^{-\delta_{i, j, k} t} . }
\end{aligned}
$$

Наступний етап полягає обчисленні інтегральних перетворень від добутку шуканих функцій у конвективній частині квазілінійних рівнянь Нав'є-Стокса - $u_{x} \partial u_{x} / \partial x, u_{y} \partial u_{x} / \partial y, u_{z} \partial u_{x} / \partial z$ у першому рівнянні, $u_{x} \partial u_{y} / \partial x, u_{y} \partial u_{y} / \partial y, u_{z} \partial u_{y} / \partial z-$ у другому та $u_{x} \partial u_{z} / \partial x$, $u_{y} \partial u_{z} / \partial y, u_{z} \partial u_{z} / \partial z$ у третьому рівнянні системи. Те саме стосується й рівняння відносно температури потока рідини або газу.

Добуток виразів типу (2), (3) і застосування інтегральних перетворень за просторовими змінними дає вираз вигляду

$$
\sum_{i=1}^{N_{x}} \sum_{j=1}^{N_{y}} \sum_{k=1}^{N_{z}} \sum_{l=1}^{N_{x}} \sum_{m=1}^{N_{y}} \sum_{n=1}^{N_{z}} U 3_{i, j, k} e^{-\delta x_{i, j, k} t} V 3_{l, m, n} e^{-\delta_{i, j, k} t}
$$

Виконання подальших ітерацій кожного разу призводить до подвоєння сум відносно часової змінної, що фрактично унеможливлює подальше використання такого вигляду виразів.

У зв'язку з цим у роботі вирішуеться проблема еквівалнтного спрощення виразів вигляду (5) таким чином, щоб уніфікувати отримані розв'язання з метою їхнього подальшого використання для розв'язання квазілінійної системи рівнянь Нав'є-Стокса.

У роботі пропонується алгоритм еквівалентного спрощення, що грунтується на застосуванні апарату ланцюгових дробів [3].

Застосуємо до виразу (5) інтегральне перетворення за Лапласом. Маємо

$$
\sum_{i=1}^{N_{x}} \sum_{j=1}^{N_{y}} \sum_{k=1}^{N_{z}} \sum_{l=1}^{N_{x}} \sum_{m=1}^{N_{y}} \sum_{n=1}^{N_{z}} \frac{R_{i, j, k, l, m, n}}{p+\delta x_{i, j, k}+\delta_{l, m, n}} .
$$

Розглянемо спочатку часткову суму вигляду

$$
Y(p)=\sum_{n=1}^{N} \frac{R_{n}}{p+\delta_{n}} .
$$

Подамо їі у вигляді дробово-раціональної функції 


$$
Y(p)=\frac{\sum_{n=0}^{N-1} b_{n} p^{n}}{\sum_{n=0}^{N} a_{n} p^{n}} .
$$

Застосування алгоритму еквівалентного спрощення [3] дає можливість отримати замість (8) такий вираз:

$$
Y(p) \approx \frac{b_{0}+b_{1} p}{a_{0}+a_{1} p+a_{2} p^{2}} .
$$

У просторі оригіналів цьому виразу відповідае

$$
y(t)=e^{-\alpha t}\left[A \varphi_{1}(t)+B \varphi_{2}(t)\right],
$$

де

$$
\begin{aligned}
& \varphi_{1}(t)=\left(\begin{array}{cc}
\cos \omega t, & \omega>0 \\
\cosh \omega t, & \omega<0 .
\end{array}\right. \\
& \varphi_{2}(t)=\left(\begin{array}{cc}
\sin \omega t, & \omega>0 \\
\sinh \omega t, & \omega<0 .
\end{array}\right.
\end{aligned}
$$

Повторне застосування алгоритму (8)-(9) до решти складових ряду (5) дозовляє отримати вираз вигляду (10). Обгрунтування такого підходу - будь-яка система високого порядку наближено веде себе як система другого порядку із запізненням.

Отже,

$$
\begin{gathered}
\sum_{i=1}^{N_{x}} \sum_{j=1}^{N_{y}} \sum_{k=1}^{N_{z}} \sum_{l=1}^{N_{x}} \sum_{m=1}^{N_{y}} \sum_{n=1}^{N_{z}} U 3_{i, j, k} e^{-\delta x_{i, j, k} t} V 3_{l, m, n} e^{-\delta_{i, j, k} t} \approx \\
\approx e^{-\alpha t}\left[A \varphi_{1}(t)+B \varphi_{2}(t)\right] .
\end{gathered}
$$

Тоді розв'язання, наприклад, першого рівняння (1) системи квазілійних рівнянь Нав'є-Стокса можна наближено подати у вигляді фрункції

$$
\begin{gathered}
u_{x}^{(1)}(x, y, z, t)=u_{x}^{(0)}(x, y, z, t) \\
\sum_{i=1}^{N_{x}} \sum_{j=1}^{N_{y}} \sum_{k=1}^{N_{z}} X_{i}\left(\alpha_{i}, x\right) Y_{j}\left(\beta_{i, j}, y\right) Z_{k}\left(\gamma_{i, j, k}, z\right) \times \\
\times e^{-\alpha_{i, j, k} t}\left[A_{i, j, k} \varphi_{1}\left(\omega_{i, j, k} t\right)+B_{i, j, k} \varphi_{2}\left(\omega_{i, j, k} t\right)\right] .
\end{gathered}
$$

Похибки, що накопичуються за рахунок такої апроксимації, поперше, не є суттєві (рис. 1), по-друге, їх можна скопенсувати за рахунок додаткових ітерацій під час розв'язання системи рівнянь. 


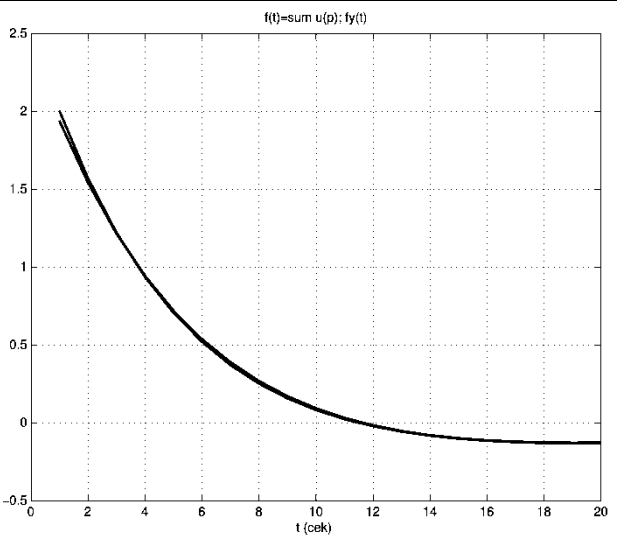

Рис. 1 - Похибки, що накопичуються за рахунок апроксимації

Наведений алгоритм може ефективно застосовуватися до розв'язання широкого класу нестаціонарних нелінійних рівнянь математичної фрізики.

\section{Список використаних джерел}

1. Зеленський К.X. Ітераційний метод розв'язання нелінійних крайових задач: наукові нотатки / К.Х. Зеленський. Міжв. збірник. Вип. 26.-Луцьк, ЛНТУ, 2009.-С.92-100.

2. Теплообмен и гидродинамика в полях цент

3. Халатов А. А. Робежных массовых сил. Том 3.- Закрученные потоки: / А. А. Халатов, А. А. Авраменко, И. В. Шевчук // Институт техн. теплофизики НАНУ, 2000. -474 с.

4. Зеленський К. Х. Комп'ютерні методи прикладної математики/ К.Х. Зеленський, В. М. Ігнатенко, О. П. Коц // К.: Наукова думка, 2002. - 480 с.

Отримано 20.04.2015 p. 